\title{
EFFECT OF ADDING MAGNESIUM SULFATE TO BUPIVACAINE ON ULTRASOUND GUIDED INTERSCALENE NERVE BLOCK
}

\author{
By
}

\author{
Ragab Asaad Hamdan Mahmoud, Anwar Mohamed Mostafa Al- \\ Hassanin and Amr Soliman Abd El-Maged Hamrosh
}

Anesthesiology and Intensive Care Department, Faculty of Medicine, Al- Azhar University

\begin{abstract}
Background: An effective pain therapy to block or modify the physiologic responses to stress has become an essential component of anesthesia for adequate postoperative pain relief.

Objective: This work is aimed to evaluate effect of adding magnesium sulfate to long acting local anesthetic as bupivacaine on ultra sound guided inter scalene nerve block undergoing elective upper limb surgery.

Patients and Methods: 60 Adult patients were included study and randomized into two equal groups; Magnesium Group received bupivacaine plus magnesium sulfate, and Saline Group received bupivacaine plus normal saline $2 \mathrm{ml}$. [The demographic data (age, sex, height, weight and ASA scoring) showed no statistical significance between 2 groups]. The time taken to stimulate the brachial plexus and the onset of block were recorded. The regain of sensation and motor power were checked at regular intervals. Patient and surgeon satisfaction were questioned. The study was conducted in Al-Azhar University Hospitals (AlHussein and Bab-Shaarya), from December 2019 till June 2020.

Results: The duration of sensory and motor block, magnesium group was statistically significant compared to saline group [Mean and (standard deviation 789(135), 788(120) minvs710 (150), 720 (135) min, $\mathrm{P}=0.038$ vs. 0.042 respectively]. Patient satisfaction was statistically significant in favor to the magnesium group. On the other hand, there was no significant difference in surgeon satisfaction between both groups.
\end{abstract}

Conclusion: The addition of magnesium sulfate to a bupivacaine for interscalene nerve block prolongs the duration of analgesia and reduces postoperative pain.

Keywords: Magnesium Sulfate, Bupivacaine, U/S Guided Interscalene Nerve Block.

\section{INTRODUCTION}

An ever increasing demand for regional anesthesia from patients and surgeons matches the growing realization that regional anesthesia can provide superior pain management and perhaps improve patient outcomes to meet evolving expectations for ambulatory, cost-effective surgery (Jee et al., 2013).

Aging population presents with an increasing range of co-morbidities, demanding a wider choice of surgical anesthetic options including the use of a variety of regional techniques in conjugation with general anesthesia to optimize clinical care, while at the same time reducing the risks of complications. Thus, the practice of regional anesthesia remains an art for many practitioners and consistent success with these techniques often appears to be limited to anesthesiologists who are regional anesthesia enthusiasts (Gupta et al., 2013). 
With modern anesthetic techniques, recovery after surgery can be rapid, smooth and complete. However, in many day-case patients, regional anesthetic techniques might be preferable. Regional anesthesia can reduce or avoid the hazards and discomfort of general anesthesia including sore throat, airway trauma, and muscle pain, but it also offers a number of advantages to outpatients undergoing surgery. These techniques provide analgesia without sedation, prolonged postoperative analgesia and allow earlier patient's discharge. Regional anesthesia reduces the requirements of opioids, reducing the incidence of postoperative nausea and vomiting. It can be used alone, in combination with sedation or as a part of balanced analgesia with general anesthesia (Stewart et al., 2012).

The ideal in the practice of regional anesthesia would be the ability to precisely deliver to the target nerve exactly the right dose of local anesthetic without incurring any risk of damage to the nerve or its related structures taking in consideration that nerves are not blocked by the needle but by the local anesthetic around. The introduction around 30 years ago of electric stimulation (ES) as an objective means for identifying needlenerve proximity was an integral step towards transforming regional anesthesia into a 'science' (Griffin and Nicholls, 2010).

Interscalene brachial plexus block (ISBPB) is indicated for anesthetic and analgesic purposes for shoulder and upper arm surgeries. The technique was modified and used a more cranial puncture site with a more tangential orientation of the needle (Marhofer et al., 2011).
Different technical modalities are used for identifying and locating the brachial plexus in the interscalene area. Conventional methods include electric stimulation and patient-reported paresthesia which rely on surface landmark identification in a semi-blind manner (Gupta et al., 2013).

Ultrasound guidance has improved the success and decreased the complication rate in regional anesthesia in general. The use of two-dimensional ultrasonic imaging to localize the brachial plexus has been highly successful in several approaches. Modern ultrasound machines are capable of imaging individual roots to their cords in the infraclavicular region. The sonographic image can be used to guide the injection needle while minimizing the risk of injury of adjacent structures (Cullen and Ferguson, 2012).

The use of Ultrasound for nerve blocks was first reported by Griffin and Nicholls. (2010) that performed supraclavicular. Brachial plexus block with the help of a Doppler US blood-flow detector to aid identification of the subclavian artery and vein.

Sheppard and colleagues in 1998, while not specifically describing ultrasound for nerve blocks, evaluated the ability of ultrasound to visualize components of the brachial plexus.

Most of the studies of ultrasound guidance in regional anesthetic practice have looked at one or more of the various approaches to the brachial plexus, some using ultrasound to identify and mark the skin over blood vessels and others using it to guide the needle or catheter to the nerve (Marhofer et al., 2011). 
The aim of the study was to evaluate the effect of adding magnesium sulfate to long acting local anesthetic as bupivacaine on U/S guided Inter scalene nerve block for anesthesia, prolongation the duration of analgesia and improving the analgesia Quality.

\section{PATIENTS AND METHODS}

A prospective, randomized controlled clinical trial was conducted in Al-Azhar University Hospitals. It included 60 patients aged (18 to 60 years) undergoing scheduled for upper limb injury repair. A written informed consent was obtained from every patient after explaining the procedure.

Patients were divided into 2 equal groups receiving different anesthetic techniques.

Magnesium Group received $0.5 \%$ bupivacaine $20 \mathrm{~mL}$ (1: 200,000 epinephrines) plus $10 \%$ magnesium sulphate $2 \mathrm{~mL}$, and saline Group received $0.5 \%$ bupivacaine $20 \mathrm{~mL}$ (1: 200,000 epinephrine) plus normal saline $2 \mathrm{~mL}$. All local anesthetic solutions were prepared immediately before administration upon arrival in the preoperative regional block room, standard monitoring was applied and patients received midazolam 0.02 $\mathrm{mg} / \mathrm{kg}$ IV before the procedure.

The time corresponding to the end of local anesthetic administration was recorded as the baseline for the time interval. All of the interscalene nerve blocks were performed by a single anesthesiologist who was experienced in this technique and blinded to group allocation.
The study data was recorded and patients were evaluated every minute until $30 \mathrm{~min}$ after the end of local anesthetic injection by the anesthesiologist who performed the interscalene nerve block and blinded to group allocation.

Sensory block was assessed by pinprick test using a three-point scale in the C4 and C5 sensory dermatome distribution and compared with the contralateral arm as a reference: $0=$ normal sensation; $1=$ loss of sensation of pinprick (analgesia); and $2=$ loss of sensation of touch (anesthesia).

After surgery, patients were evaluated every ten minutes until complete resolution of sensory and motor blockade. The duration of sensory block was defined as the time interval between the end of local anesthetic administration and restoration of normal sensation (i.e., sensory score 0 compared with the contralateral arm as a reference).

The duration of motor block was defined as the time interval between the end of local anesthetic administration and the recovery of complete motor function. Block success was defined as loss of sensation to pinprick (sensory score $\mathrm{C} 1$ ) in the C4 and C5 sensory dermatome distributions measured $30 \mathrm{~min}$ after the end of local anesthetic injection.

\section{Inclusion criteria:}

- Age: between 18-60 years of age.

- Undergoing Upper limb injury repair.

- Patients of ASA I-II.

\section{Exclusion criteria:}

A history of cardiac, hepatic, or renal disease; chronic treatment with calcium channel blocker; hypomagnesaemia; 


\section{RAGAB ASAAD HAMDAN MAHMOUD et al.,}

contraindications to interscalene nerve block (bleeding disorders local or systemic infection); and inability to comprehend the numeric rating scale (NRS) for pain assessment.

\section{Statistical Analysis:}

Data were collected, revised, coded and entered to the Statistical Package for Social Science (IBM SPSS) version 23.Armonk, NY; IBM Corp. Numerical date will be explored for normality by checking the distribution of data and using tests of normality (Kolmogorov-Smimov and Shapiro-Wilk tests). The quantitative data were presented as mean, standard deviations, Median and ranges when data found parametric. Also qualitative variables were presented as number and percentages. The comparisons between groups with qualitative data were done by using Chi-square test. The comparison between two groups with quantitative data and parametric distribution were done by using Independent t-test. For nonparametric data, Mann Whitney U Test will be used to compare between the two groups. The confidence interval was set to 95\% and the margin of error accepted was set to $5 \%$. So, the $\mathrm{p}$-value was considered significant as when $\mathrm{P} \leq 0.05$

\section{RESULTS}

The demographic data (sex, age, height, weight, ASA) showed no statistical significance between groups; as the $\mathrm{p}$-value were $(0.194,0.410,0.193$, 0.392 and 0.713 respectively) Table (1).

Table (1): Comparison between groups as regard demographic data

\begin{tabular}{|c|c|c|c|c|c|}
\hline \multicolumn{2}{|c|}{ Groups } & $\begin{array}{c}\text { Bupivacaine } \\
\text { +Saline }\end{array}$ & $\begin{array}{c}\text { Bupivacaine } \\
+\mathrm{Mg}\end{array}$ & \multirow{2}{*}{ Test value } & \multirow{2}{*}{ p-value } \\
\hline \multicolumn{2}{|c|}{$\begin{array}{l}\text { Demographic } \\
\text { data }\end{array}$} & No. $=30$ & No. $=30$ & & \\
\hline \multirow{2}{*}{ Sex } & Female & $14(46.7 \%)$ & $19(63.3 \%)$ & \multirow{2}{*}{$1.684^{*}$} & \multirow{2}{*}{0.194} \\
\hline & Male & $16(53.3 \%)$ & $11(36.7 \%)$ & & \\
\hline \multirow{2}{*}{$\begin{array}{c}\text { Age } \\
\text { (years) }\end{array}$} & Mean \pm SD & $59.07 \pm 11.98$ & $56.20 \pm 14.65$ & \multirow{2}{*}{$0.831 \bullet$} & \multirow{2}{*}{0.410} \\
\hline & Range & $20.0-82.0$ & $28.0-75.0$ & & \\
\hline \multirow{2}{*}{$\begin{array}{l}\text { Height } \\
(\mathrm{cm})\end{array}$} & Mean \pm SD & $169.70 \pm 11.95$ & $173.53 \pm 10.55$ & \multirow{2}{*}{$1.316^{\bullet}$} & \multirow{2}{*}{0.193} \\
\hline & Range & $150.0-186.0$ & $160.0-190.0$ & & \\
\hline \multirow{2}{*}{ Weight } & Mean \pm SD & $80.57 \pm 13.70$ & $77.73 \pm 11.70$ & \multirow{2}{*}{$-0.863 \bullet$} & \multirow{2}{*}{0.392} \\
\hline & Range & $60.0-120.0$ & $68.0-108.0$ & & \\
\hline \multirow{2}{*}{ ASA } & $\mathrm{I}$ & $13(43.3 \%)$ & $15(50.0 \%)$ & \multirow{2}{*}{$0.676^{*}$} & \multirow{2}{*}{0.713} \\
\hline & II & $15(50.0 \%)$ & $12(40.0 \%)$ & & \\
\hline
\end{tabular}

There was a statistically significant difference higher mean in Bupivacaine plus saline compared to Bupivacaine plus
$\mathrm{Mg}$ according to onset of sensory block (min), P-value 0.037 (Table 2). 
Table (2): Onset of sensory block

\begin{tabular}{|c|c|c|c|c|}
\hline \multirow{2}{*}{$\begin{array}{l}\text { Onset of Groups } \\
\text { sensory block } \\
\text { (min) }\end{array}$} & $\begin{array}{c}\text { Bupivacaine } \\
+ \text { Saline }\end{array}$ & $\begin{array}{c}\text { Bupivacaine } \\
+\mathbf{M g}\end{array}$ & \multirow{2}{*}{ Test value } & p-value \\
\cline { 2 - 3 } Mean \pm SD & No. $=\mathbf{3 0}$ & No. $=\mathbf{3 0}$ & \\
\hline Median(IQR) & $4.25 \pm 1.98$ & $3.27 \pm 1.45$ & \multirow{2}{*}{2.187} & \multirow{2}{*}{0.037} \\
\hline Range & $4(2)$ & $3(2)$ & \\
\hline
\end{tabular}

A statistically significant higher mean in Bupivacaine plus saline compared to Bupivacaine plus $\mathrm{Mg}$ according to onset of motor block (min), with P-value 0.029 (Table 3).

Table (3): Onset of motor block

\begin{tabular}{|c|c|c|c|c|}
\hline Onset of Groups & $\begin{array}{l}\text { Bupivacaine } \\
\text { +Saline }\end{array}$ & $\begin{array}{c}\text { Bupivacaine } \\
+\mathrm{Mg}\end{array}$ & Test value & p-value \\
\hline & No. $=30$ & No. $=\mathbf{3 0}$ & & \\
\hline Mean \pm SD & $7.20 \pm 2.4$ & $5.8 \pm 2.7$ & \multirow{3}{*}{2.552} & \multirow{3}{*}{0.029} \\
\hline Median (IQR) & $7(2)$ & $6(3)$ & & \\
\hline Range & $1-8$ & $3-10$ & & \\
\hline
\end{tabular}

The block was considered a failure if it required supplementations with local anesthetic infiltration, intravenous opioids, or administration of general anesthetics. The block was complete and successful in 15 patients in Bupivacaine saline group $(50 \%)$ and 23 patients in Bupivacaine $\mathrm{Mg}$ group (76.3\%), with total of $63.15 \%$. Supplementary analgesia needed for 10 patients in Bupivacaine saline group (33.3\%) and 6 patients for Bupivacaine $\mathrm{Mg}$ group (20\%), with total of $26.6 \%$. Another attempt or technique was needed for 5 patients in Bupivacaine saline group (16.7\%) and 1 patient in Bupivacaine $\mathrm{Mg}$ group (3.3\%), with total of $9.8 \%$. This showed statistical significance as the $\mathrm{P}$ value was 0.041 (Table 4).

Table (4): Success or failure of the block

\begin{tabular}{|c|c|c|c|c|c|c|}
\hline \multirow{2}{*}{ Groups } & \multicolumn{2}{|c|}{$\begin{array}{c}\text { Bupivacaine } \\
\text { +Saline }\end{array}$} & \multicolumn{2}{c|}{$\begin{array}{c}\text { Bupivacaine } \\
+ \text { Mg }\end{array}$} & & \multirow{2}{*}{ Total } \\
\cline { 2 - 7 } & No. & $\%$ & No. & \% & No. & \% \\
\hline 0 & 0 & $0.0 \%$ & 0 & $0.0 \%$ & 0 & $0.0 \%$ \\
\hline 1 & 15 & $50.0 \%$ & 23 & $76.7 \%$ & 38 & $63.3 \%$ \\
\hline 2 & 10 & $33.3 \%$ & 6 & $20.0 \%$ & 16 & $26.7 \%$ \\
\hline 3 & 5 & $16.7 \%$ & 1 & $3.3 \%$ & 6 & $10.0 \%$ \\
\hline Total & $\mathbf{3 0}$ & $\mathbf{1 0 0}$ & $\mathbf{3 0}$ & $\mathbf{1 0 0}$ & $\mathbf{6 0}$ & $\mathbf{1 0 0}$ \\
\hline Chi-square test & \multicolumn{7}{|c|}{$\mathbf{6 . 4 1 0}$} & & \\
\hline P-value & \multicolumn{7}{|c|}{$\mathbf{0 . 0 4 1}$} & & \\
\hline
\end{tabular}

Time to sensory regression was confirmed by regaining sensory response to pin prick test. This showed statistical significance as the $\mathrm{P}$ value was 0.038 (Table 5). 
RAGAB ASAAD HAMDAN MAHMOUD et al.,

Table (5): Duration of the sensory block

\begin{tabular}{|c|c|c|c|c|}
\hline Duration $\quad$ Groups & $\begin{array}{c}\text { Bupivacaine } \\
+ \text { +Saline }\end{array}$ & $\begin{array}{c}\text { Bupivacaine } \\
+\mathrm{Mg}\end{array}$ & \multirow{2}{*}{$\begin{array}{c}\text { Test } \\
\text { value }\end{array}$} & \multirow{2}{*}{$\begin{array}{c}\text { p- } \\
\text { value }\end{array}$} \\
\hline $\begin{array}{l}\text { of the sensory } \\
\text { block }(\min )\end{array}$ & No. $=\mathbf{3 0}$ & No. $=30$ & & \\
\hline Mean \pm SD & $710.70 \pm 150.70$ & $789.30 \pm 135.60$ & \multirow{2}{*}{2.124} & \multirow{2}{*}{0.038} \\
\hline Range & $483-961$ & $511-1093$ & & \\
\hline
\end{tabular}

Time to motor regression was confirmed by regaining of the ability to move relevant muscles upon verbal

command. This showed statistical significance as the $\mathrm{P}$ value is 0.042 (Table 6).

Table (6): Duration of the motor block

\begin{tabular}{|c|c|c|c|c|}
\hline \multirow{2}{*}{$\begin{array}{l}\text { Duration } \\
\text { of the motor } \\
\text { block (min) }\end{array}$} & $\begin{array}{c}\text { Bupivacaine } \\
+ \text { Saline }\end{array}$ & $\begin{array}{c}\text { Bupivacaine } \\
+ \text { Mg }\end{array}$ & \multirow{2}{*}{$\begin{array}{c}\text { Test } \\
\text { value }\end{array}$} & $\begin{array}{c}\text { p- } \\
\text { value }\end{array}$ \\
\cline { 1 - 3 } Mean \pm SD & No. $=\mathbf{3 0}$ & No. $=\mathbf{3 0}$ & \\
\hline Range & $420.11 \pm 135.30$ & $788.94 \pm 120.40$ & 2.082 & \multirow{2}{*}{0.042} \\
\hline
\end{tabular}

No complications happened in 24 patients in Bupivacaine plus saline group $(80 \%)$, and 26 patients in Bupivacaine plus $\mathrm{Mg}$ group $(86.7 \%)$ with total percentage of $83.3 \%$. Recurrent laryngeal nerve palsy (hoarsness of voice occurred in 1 patient in Bupivacaine plus saline group $(3.3 \%)$ and never occurred in Bupivacaine plus saline group. Horner syndrome (ptosis, miosis, anhydrosis) due to accidental cervical plexus block occurred in 2patients in Bupivacaine plus saline group $(6.7 \%)$ and in only 1 patient in Bupivacaine plus $\mathrm{Mg}$ group (3.3\%) with total of $5 \%$. paresthesia didn't occur in Bupivacaine plus saline group while it happened in 2 cases in Bupivacaine plus $\mathrm{Mg}$ group $(6.7 \%)$ with total of $3.3 \%$. bloody tap occurred in 1 patients in Bupivacaine plus saline group (3.3\%) and didn't happen in Bupivacaine plus $\mathrm{Mg}$ group . phrenic nerve stimulation occurred in 2 cases in Bupivacaine plus saline group $(6.7 \%)$ and in 1 case only in Bupivacaine plus Mg group (3.3\%). This showed no statistical significance as the $\mathrm{P}$ value was 0.448 (Table 7).

Table (7): Occurrence of complications.

\begin{tabular}{|c|c|c|c|c|c|c|}
\hline \multirow{2}{*}{ Complications Groups } & \multicolumn{2}{|c|}{$\begin{array}{l}\text { Bupivacaine } \\
\text { +Saline }\end{array}$} & \multicolumn{2}{|c|}{$\begin{array}{c}\text { Bupivacaine } \\
+\mathrm{Mg}\end{array}$} & \multicolumn{2}{|c|}{ Total } \\
\hline & No. & $\%$ & No. & $\%$ & No. & $\%$ \\
\hline No complications & 24 & $80.0 \%$ & 26 & $86.7 \%$ & 50 & $83.3 \%$ \\
\hline $\begin{array}{l}\text { Recurrent laryngeal nerve } \\
\text { palsy }\end{array}$ & 1 & $3.3 \%$ & 0 & $0.0 \%$ & 1 & $1.7 \%$ \\
\hline Horner Syndrome & 2 & $6.7 \%$ & 1 & $3.3 \%$ & 3 & $5.0 \%$ \\
\hline Paraesthesia & 0 & $0.0 \%$ & 2 & $6.7 \%$ & 2 & $3.3 \%$ \\
\hline Bloody Tap & 1 & $3.3 \%$ & 0 & $0.0 \%$ & 1 & $1.7 \%$ \\
\hline Phrenic nerve block & 2 & $6.7 \%$ & 1 & $3.3 \%$ & 3 & $5.0 \%$ \\
\hline Total & 30 & $100.0 \%$ & 30 & $100.0 \%$ & 60 & $100.0 \%$ \\
\hline Chi-square test & \multicolumn{6}{|c|}{4.747} \\
\hline P-value & \multicolumn{6}{|c|}{0.448} \\
\hline
\end{tabular}


There was a statistically significant higher mean in Bupivacaine plus $\mathrm{Mg}$ compared to Bupivacaine plus saline according to Patient satisfaction, with $\mathrm{P}$ value 0.043 (Table 8).

Table (8): Patient's satisfaction

\begin{tabular}{|c|c|c|c|c|c|c|}
\hline \multirow{2}{*}{$\begin{array}{l}\text { Patient's } \\
\text { satisfaction }\end{array}$} & \multicolumn{2}{|c|}{$\begin{array}{l}\text { Bupivacaine } \\
\text { +Saline }\end{array}$} & \multicolumn{2}{|c|}{$\begin{array}{c}\text { Bupivacaine } \\
+\mathrm{Mg}\end{array}$} & \multirow{2}{*}{$\begin{array}{l}\text { Test } \\
\text { value }\end{array}$} & \multirow{2}{*}{$\begin{array}{c}\text { p- } \\
\text { value }\end{array}$} \\
\hline & No. & $\%$ & No. & $\%$ & & \\
\hline 1 & 9 & $30.0 \%$ & 2 & $6.7 \%$ & \multirow{4}{*}{8.125} & \multirow{4}{*}{0.043} \\
\hline 2 & 5 & $16.7 \%$ & 2 & $6.7 \%$ & & \\
\hline 4 & 6 & $20.0 \%$ & 10 & $33.3 \%$ & & \\
\hline 5 & 10 & $33.3 \%$ & 16 & $53.3 \%$ & & \\
\hline
\end{tabular}

\section{DISCUSSION}

Successful peripheral nerve and plexus blockade can provide an excellent anesthetic outcome, either when used alone, or in combination with general anesthesia. In either setting there is the possibility of prolonged post-operative analgesia. When PNB is used as the sole anesthetic technique, additional advantages may be present from the avoidance of general anesthesia complications, such as post- operative nausea and vomiting and cognitive dysfunction. PNB may also result in earlier hospital discharge (Chandrakantan and Glass, 2011).

It is helpful to consider what features an ideal peripheral nerve block technique should offer; an ideal peripheral nerve block technique should be safe, successful, easy, acceptable to patients, and economical.

Magnesium is a competitive N-methyl$\mathrm{D}$-aspartate receptor - receptor antagonist and inhibits the voltage dependent ion channels. In addition, it seems that magnesium sulfate increases the length of the block in intravenous regional anesthesia (Mirkheshti et al., 2012).
Therefore, improving the quality of local anesthetics in regional and local blocks as well as the management of postoperative acute pain is important for patients who suffer from the pain after surgery such as upper limb injury surgery.

This study investigated the effects of adding magnesium sulfate with $0.5 \%$ bupivacaine in inter scalene brachial plexus blocks to prolong the duration of sensory and motor blockage and diminish postoperative acute pain for the patient.

In this study, the mean duration of the sensory and motor blocks in the $0.5 \%$ bupivacaine plus magnesium Group was significantly longer than in the $0.5 \%$ bupivacaine plus normal saline. We also assessed the onset of the sensory and motor blocks between the two groups.

The onset time of sensory block, i.e. the time from when the injection was completed and the first symptoms of anesthesia in the limb were established, was significantly shorter for the $0.5 \%$ bupivacaine plus magnesium group than for the control group who received $0.5 \%$ bupivacaine plus normal saline group.

In another study conducted by Radwan et al. (2012), intra-articular injections of 


\section{RAGAB ASAAD HAMDAN MAHMOUD et al.,}

bupivacaine with magnesium resulted in longer periods of analgesia (duration) when compared with the control group that received $0.5 \%$ bupivacaine plus normal saline.

Similar study conducted by Sonali et al. (2012) reported that the addition of magnesium increased the duration time of an epidural analgesia. Wahba and Tammam (2014) investigated the effect of magnesium in intravenous regional anesthesia and reported that the onset of sensory and motor analgesia was faster in the magnesium group than in the saline group.

\section{CONCLUSION}

The additions of magnesium sulphate to a bupivacaine for interscalene nerve block prolongs the duration of analgesia, improve quality of analgesia and reduces postoperative pain.

\section{REFERENCES}

1. Chandrakantan A and Glass PS (2011): Multimodal therapies for postoperative nausea and vomiting, and pain. British Journal of Anaesthesia, 107(1):i27-40.

2. Cullen A and Ferguson A. (2012): Perioperative management of the severely obese patient: a selective pathophysiological review. Canadian Journal of Anesthesia/Journal canadiend' anesthésie, 59(10):974-96.

3. Griffin $\mathbf{J}$ and Nicholls B (2010): Ultrasound in regional anaesthesia. Anaesthesia, 65:1-2.

4. Gupta RK, Lane J, Allen B and Shi Y and Schildcrout JS (2013): Improving needle visualization by novice residents during an inplane ultrasound nerve block simulation using an in-plane multi angle needle guide. Pain Medicine, 14(10):1600-7.
5. Jee H, Lee JH, Kim J, Park KD, Lee WY and Park Y (2013): Ultrasound-guided selective nerve root block versus fluoroscopyguided trans foraminal block for the treatment of radicular pain in the lower cervical spine: a randomized, blinded, controlled study. Skeletal Radiology, 42(1):69-78.

6. Marhofer P, Harrop-Griffiths W, Willschke $H$ and Kirchmair L (2011): Fifteen years of ultrasound guidance in regional anaesthesia: Part 2-recent developments in block techniques, British Journal of Anaesthesia, 104(6):673-83.

7. Mirkheshti, A., Aryani, M. R., Shojaei, P. and Dabbagh, A. (2012): The effect of adding magnesium sulfate to lidocaine compared with paracetamol in prevention of acute pain in hand surgery patients under intravenous regional anesthesia (IVRA). International Journal of Preventive Medicine, 3(9):616.

8. Radwan Y. A., Al feky A.A. and Faramawi M. F. (2012): Intra articular injection of magnesium sulphate and / or bupivacaine for post-operative analgesia after arthroscopic knee surgery .Anesth Analg, 106(5):1548-52.

9. Sonali B, Sujata S, Mridula P, Rakesh G and Rajesh S (2012): Evaluation of single epidural bolus dose of magnesium as an adjuvant to epidural fentanyl for postoperative analgesia: A prospective, randomized, doubleblind study.Saudi J Anaeth,.(3):273-8.

10. Stewart DW, Ragg PG, Sheppard S and Chalkiadis GA (2012): The severity and duration of postoperative pain and analgesia requirements in children after tonsillectomy, orchidopexy, or inguinal hernia repair. Pediatric Anesthesia, 22(2):136-43.

11. Wahba, S. S., and Tammam, T. F. (2014): Intravenous regional anesthesia: effect of magnesium using two different routes of administration. Ain-Shams Journal of Anaesthesiology, 7(1), 65. 
تأثثير إضافة الماغنسيوم سلفات إلى البيوبافكين أثناء عملية

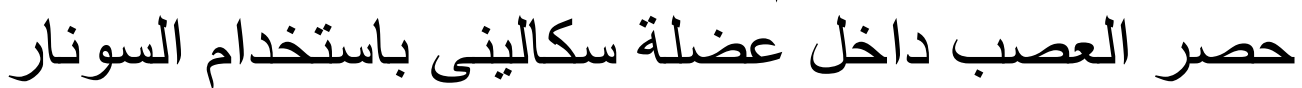
رجب أسعد حمدان محمود، أنور محمد مصطفى الحسانين، عمرو سليمان عبد المجيد

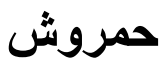

قسم التخدير والرعاية المركزة، كلية الطب، جامعة الأزهر

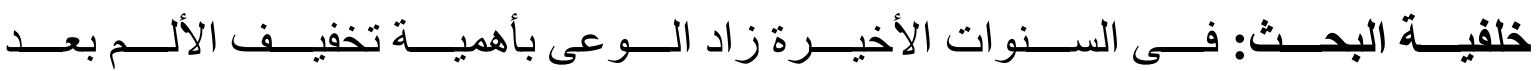

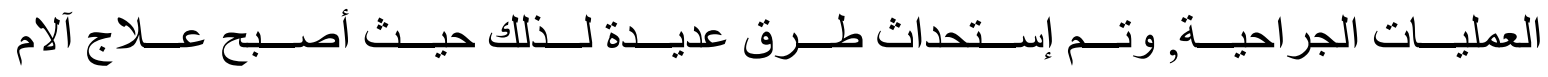

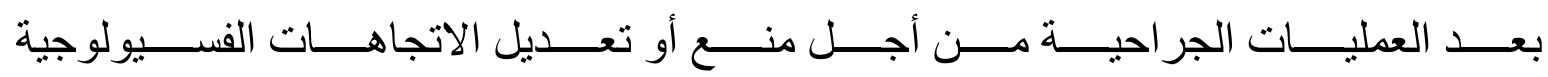
للاجهاد والضغط العصبى عنصر ا أساسيا فى علم التخدير.

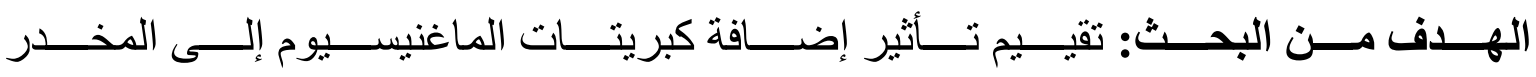

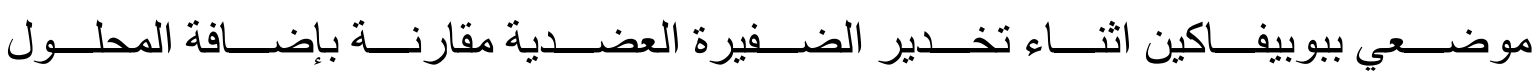

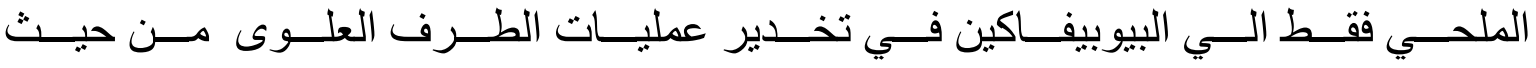

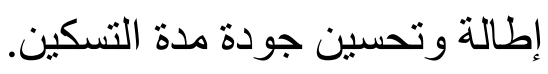

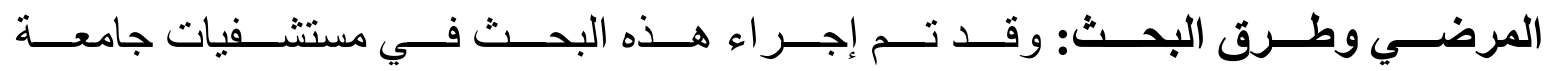

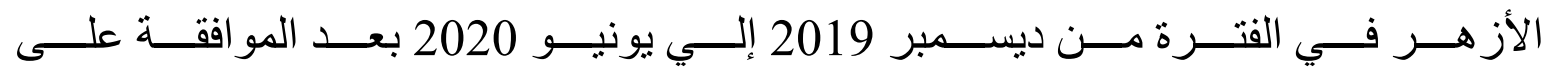

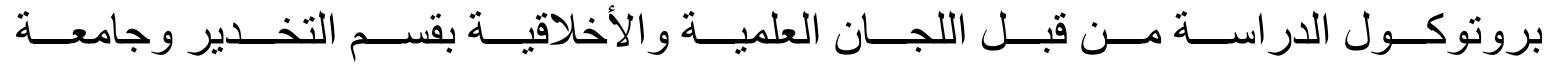

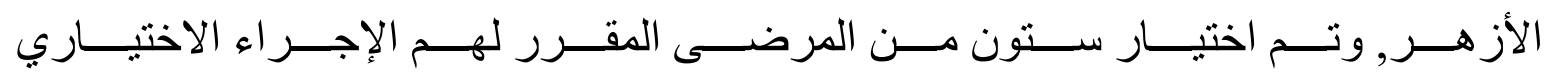

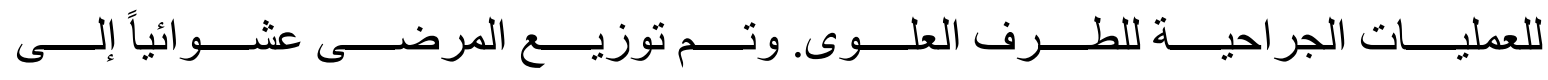

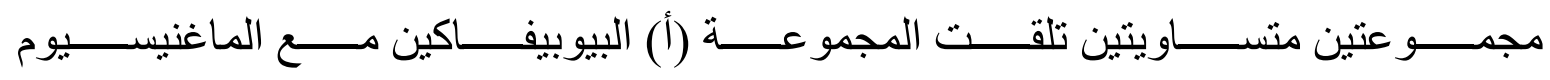

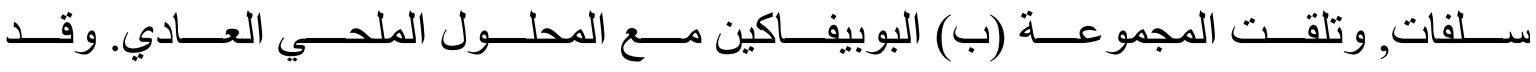

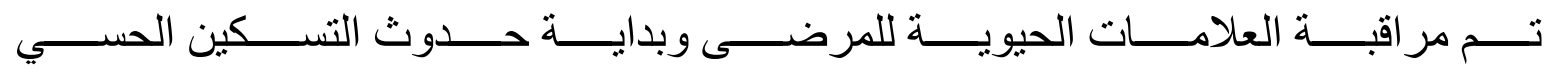

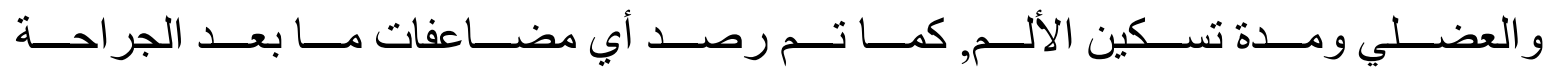

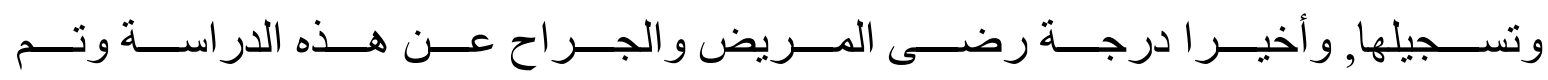
تسجيل النتائج و تحليلها إحصائيا. 


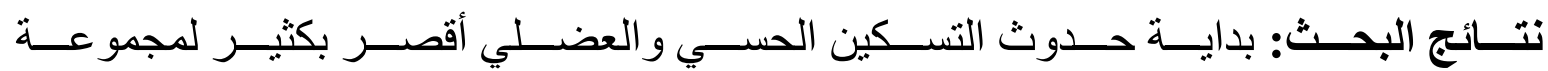

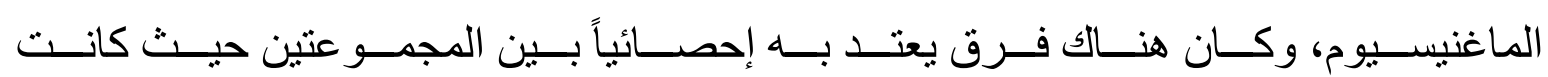

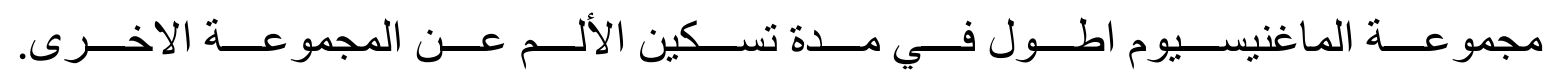

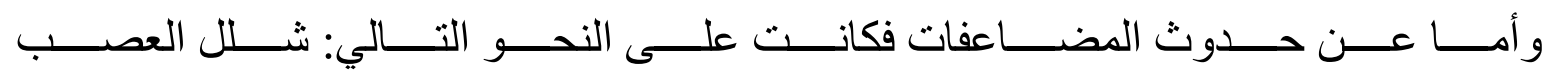

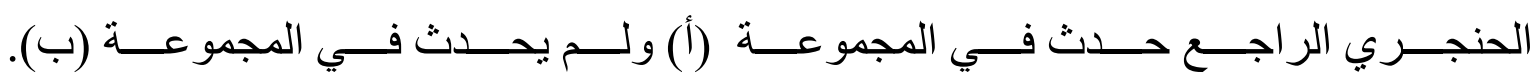

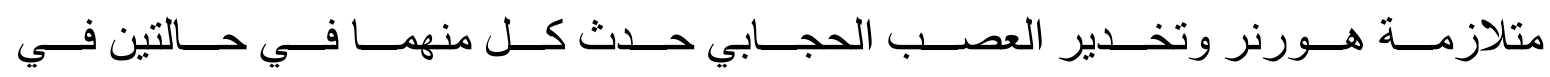

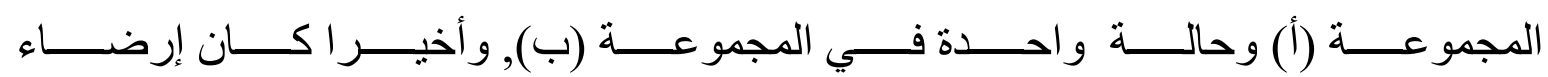

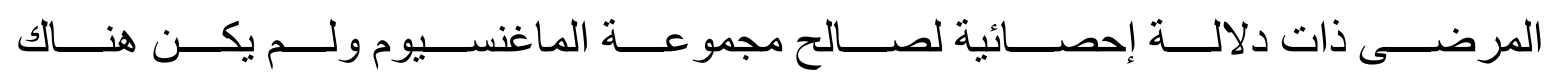
فرق كبير في رضا الجر اح بين المجمو عتين.

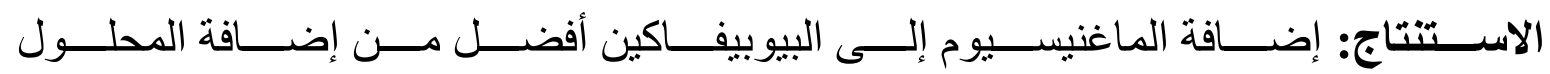

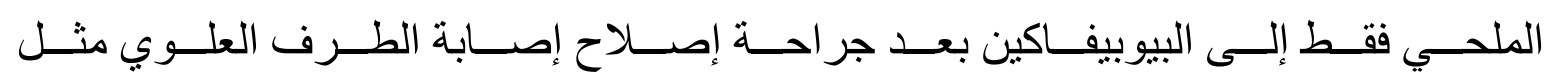

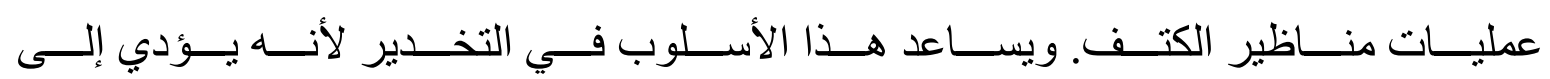
إطالة وتحسين جودة مدة التسكين. 